\title{
Educational Potential and the Situation of the Youth on the Labour Market in the European Union Regions
}

\author{
Beata BAL-DOMAŃSKA, Elżbieta SOBCZAK \\ Wrocław University of Economics, Jelenia Góra, Poland \\ \{beata.bal-domanska, elżbieta.sobczak\}@ue.wroc.pl
}

\begin{abstract}
The study is focused on the relationship between educational potential and labor market. Educational potential is defined as the resource of knowledge and skills in the region expressed by the level of formal education, the scientific potential, and the tendency to continue to improve qualifications. The labour market is represented by the young people, who enter the labour market after obtaining formal education. The purpose of the study is to assess the spatial autocorrelation of educational potential and the situation of young people in the cross-section of the NUTS-2 European Union regions in 2016. The analytical tools were spatial statistics (local and global I Moran).

The obtained results indicate strong tendency for cluster development. This was very well visible in case of the long life learning indicator and employment rate of young people neither in education nor training. The lowest tendency for clustering was observed in case of early leavers form education and training. Furthermore the results suggest the significance of education for the development of labour market for young people.
\end{abstract}

Keywords: Educational Potential, Spatial Statistics, EU NUTS-2 Regions.

\section{Introduction}

The European countries and regions face numerous developmental challenges, covering environmental, social and economic spheres. Among them social cohesion and smart growth are listed, based on knowledge, innovation and skilled workers. It is owing to high quality human capital that achieving the goal of constructing a smart growth is possible, the development of which will result in improved competitiveness of the EU countries and the increased number of attractive workplaces. The development of high quality human capital, capable of creating innovations represents a capital-intensive and time-consuming process that should be already strengthened at the level of education.

Among the basic indicators to monitor the EUROPE 2020 Strategy there are two concerning education, which confirms the importance of this phenomenon for the development of countries. Among the phenomena selected for monitoring at the EU level the following are included: the share of early school leavers to be reduced under $10 \%$ and at least $40 \%$ of 30 to 34 years old to have completed tertiary or equivalent 
education. These values differ in the cross-section of particular countries and in case of youth dropping out of school prematurely from $4 \%-4.5 \%$ (Croatia, Poland) to $16 \%$ (Italy).

In the literature a differed aspects of education are underscored. Education could be consider as a factor influencing cultural and social change, level of economic and innovativeness development, as well as a quality of social and human capital.

Education is often considered as a proxy for the human capital accumulation in the economic growth model. The investigation of the relationship between education and economic growth started in 1960s and has become one of the mainstream of research in economics. Becker [1] takes into account varying cultures and political regimes, indicates that economic earnings tend to be positively correlated to education and skill level. Additionally, his studies indicate an inverse correlation between education and unemployment. Also Selowski [10] concentrate upon education as one means of improving the labor input. He tries to extend as precisely as possible this aspect of the human capital hypothesis within the aggregate production function approach to growth. His research focused on the observation the basis of educational capital postulate is an empirical one arising from two observations: there is a positive relation between the productivity of labor and the amount of education embodied in it, and countries spend relatively a big part of their resources on education. Oancea, Pospíšil, Drăgoescu [9] has investigated the causality and the long-run relationship between economic growth and higher education in the Czech Republic and Romania in the period of 1980-2013. The results showed that higher education has an important positive effect on economic growth, although the impact level of the higher education on economic growth is different in the two countries.

Some results of the research suggested that the education level is perceived as a precondition for entering the labor market. According to evaluation of employment policy by important institutional players in two Czech regions (the Ústecký Region and the Jihočeský Region), presented by Novák, Vokoun, Stellner, Vochozka [8], the unemployed usually have no previous job experience, completed only primary education and are not willing to travel to work. The pressing problem is also the quality of education and the generous social benefits. The author underline that all the institutional players stress the need for appropriate education, which is problematic.

Investigating the educational potential and its link with the labor market attention should be paid to the possible mismatches. The job mismatches can be define as the over or under education (over-education, describes the extent to which individuals possess a level of education in excess of that required in their specific job), alternatively as the difference between the field of study of graduates and the actual demand on the labour market (skill mismatch). This problem was discussed among others by Maršíková., Urbánek [6], Chevalier, Lindley [2].

Considering the job and skills mismatches also the spatial mismatches can be analysed. Spatial mismatches occur when the amount of human capital, presenting a certain educational potential is distributed in space differently than the demand for skilled workers. Equalling of such mismatches requires educational policy changes in a given region (matching possible over a long period of time) or workforce relocation 
between regions, which is connected with migration processes (matching possible in a short period of time).

In the hereby paper educational potential is understood as the resource of knowledge and skills in a region. Educational potential is measured by the level of formal education, the scientific capital represented by the number of scientists and engineers and the tendency to improve qualifications (trainings). The conducted analysis highlights the participation of people with the highest level of education and specialized qualifications, the tendency for continuous improvement of their qualifications, and the scale of early leavers of the education process. The research was based on the assumption that the regional educational potential depends on the people with the highest and the lowest qualifications.

At this background the situation of young people, who enter the labour market after obtaining formal education was presented. Both the percentage of unemployed and those professionally active were used to characterise the situation of young people on the labour market. The situation of people on the labour market is considered one of the priority objectives of the EU policy.

The purpose of the study is to assess the spatial distribution of educational potential and the situation of young people in the cross-section of the NUTS-2 European Union regions. The study covered 265 European Union regions (NUTS-2) in 2016. The research tool used in the study was local and global $I$ Moran spatial statistics, which allowed answering the research question whether educational potential or situation of youth on the labour market indicates the regional tendency for clustering of the regions characterised by a similar situation or rather creating the socalled hot spots, i.e. regions presenting a different situation than their immediate milieu. The development of regional clusters, characterised by an expected and positive situation should be considered particularly beneficial and conductive for the creation of centres with high education potential, which can benefit from their own or their milieu resources. The clusters of regions characterised by low educational potential present a challenge for the regional socio-economic policy and require undertaking actions extending beyond the scale of one region. These activities should aim at introducing structural changes in the area of education and economy, focused on the labour market development for the highly qualified individuals.

\section{The background information and methodology of the research}

The identification of educational potential in the European Union regions was conducted using the below presented indicators:

- $S E-\%$ scientists and engineers of active population,

- ETER - population with tertiary education (levels 5-8) (\%),

- $L L$ - participation rate in education and training (last 4 weeks) of people aged 25$64(\%)$,

- $E L$ - early leavers from education and training aged 18-24 (\%), 
and situation of youth at the labour market was described by:

- YUEN - youth aged 18-24 neither in employment nor in formal or non-formal education and training $(\%)$,

- YEMPL - employment rates of young people aged 15-34 neither in education nor training $(\%)$.

The statistical information, required for the empirical research, was obtained based on Eurostat database. The study covered 265 European Union regions selected based on NUTS 2 (The Nomenclature of Territorial Units for Statistics) classification. Due to the unavailability of statistical data the analysis did not cover 11 NUTS 2 regions.

The following research procedure were applied:

- The identification of educational potential indicators.

- The identification of indicators describing the situation of the youth at the labour market.

- The identification of spatial autocorrelation of educational potential and youth at the labour market indicators using Moran's I Global.

- The identification of spatial autocorrelation of educational potential and youth at the labour market indicators using Moran's Local Statistics.

Moran's I Global and Moran's Local Statistics were used in order to identify spatial autocorrelation. Moran's Global $I$ describes the tendency across subjects to form groups of counties - clusters - characterised by a similar (favourable or unfavourable) situation $[3,7,11,12]$. Moran's Local Statistics was used to identify clusters of units with extremely different situation from the neighbouring units (hotspots) and also clusters with similar values of the phenomenon. It was crucial to define the spatial dependence pattern and, as a result, the distance matrix. For this analysis the standardised weight matrix was applied with the first-order neighbors. R CRAN program was used to perform calculations $[4,5]$.

\section{Empirical analysis results}

The results of spatial autocorrelation analysis indicate the tendency towards development of the groups of regions characterised by a similar level of educational potential (tab. 1). Positive values of Moran's I Global of approx. 0,5 indicate strong tendencies for cluster development.

Having assessed the spatial distribution of identified spatial clusters for the particular measures of educational potential and the situation of youth at the local market a certain pattern appears, which indicates either strong or weak position of the selected European Union regions. The spatial distribution of particular variable values and the respective Moran's local statistics are presented on fig. 1-6. The presentation of the results includes the distribution of the phenomenon on the cartogram, which allows the observation of spatial differentiation and the cartogram with the values of local I Moran's statistics showing the groups of regions for which the statistically significant spatial relationship was confirmed at the significance level of 0.05 . 
Table 1. Values of Moran's I Global for educational potential indicators and situation of young people at the labour market in 2016.

\begin{tabular}{c|c|c|c|c|c}
\hline \multicolumn{6}{c}{ I Moran (Global) } \\
SE & EL & LL & ETER & YEMPL & YUEN \\
\hline 0.5678 & 0.4882 & 0.8052 & 0.5896 & 0.6250 & 0.5153 \\
\hline
\end{tabular}

Scientists and engineers as percentage of active population (SE) (fig. 1): NUTS-2 EU regions show a clear tendency towards developing groups. However, only in two thirds cases the grouping covers regions characterized by a favourable situation, i.e. high percentage of human resources for science and technology (HRST), which refers to regions in the northern EU part: a large group of British regions, southern part of Sweden and the third group of Belgian and Dutch regions.

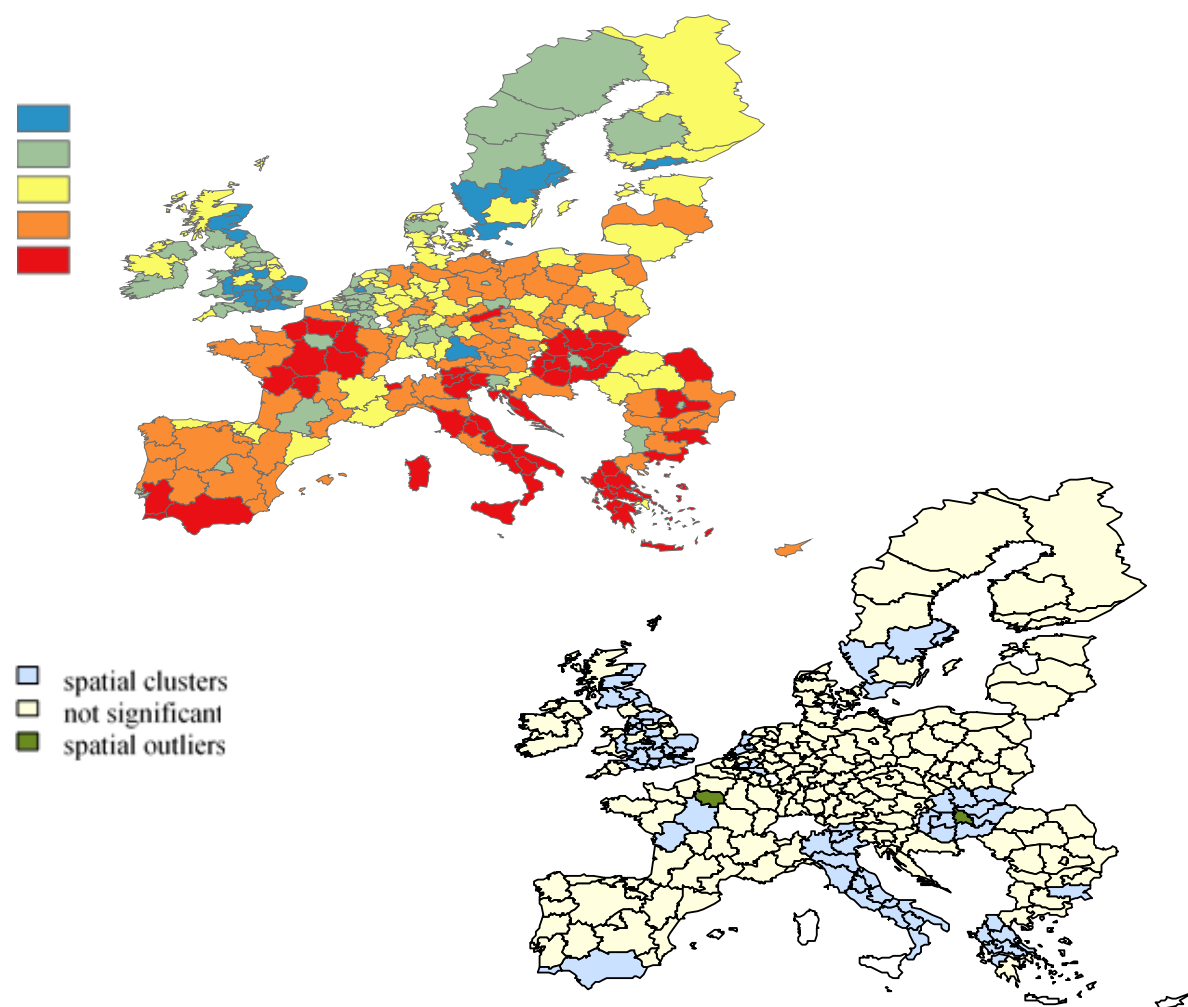

Fig. 1. Spatial distribution of Moran's local statistics (bottom) and clusters (upper) of NUTS-2 EU regions for the SE in 2016.

The other 6 clusters are created by regions featuring low human capital measured by SE, i.e.: (1) Slovak and Hungarian regions concentrated around the Hungarian region of Közép-Magyarország, which is a spatial outlier, (2) a small cluster of Bulgarian regions, (3) a very large group of regions in the tourist southern Greece, (4) in 
southern Italy, (5) in the southern part of Portuguese and Spanish border and (6) the region of Île de France to the east of the French capital, which just like the Hungarian Közép-Magyarország is a spatial outlier.In case of the regions presenting low educational potential, however clustered around the ones with high potential (e.g. Île de France, Közép-Magyarország), we can talk about the concentration of scientific activity in the centre, which can, to some extent, neutralise low scientific potential of the neighbouring regions.

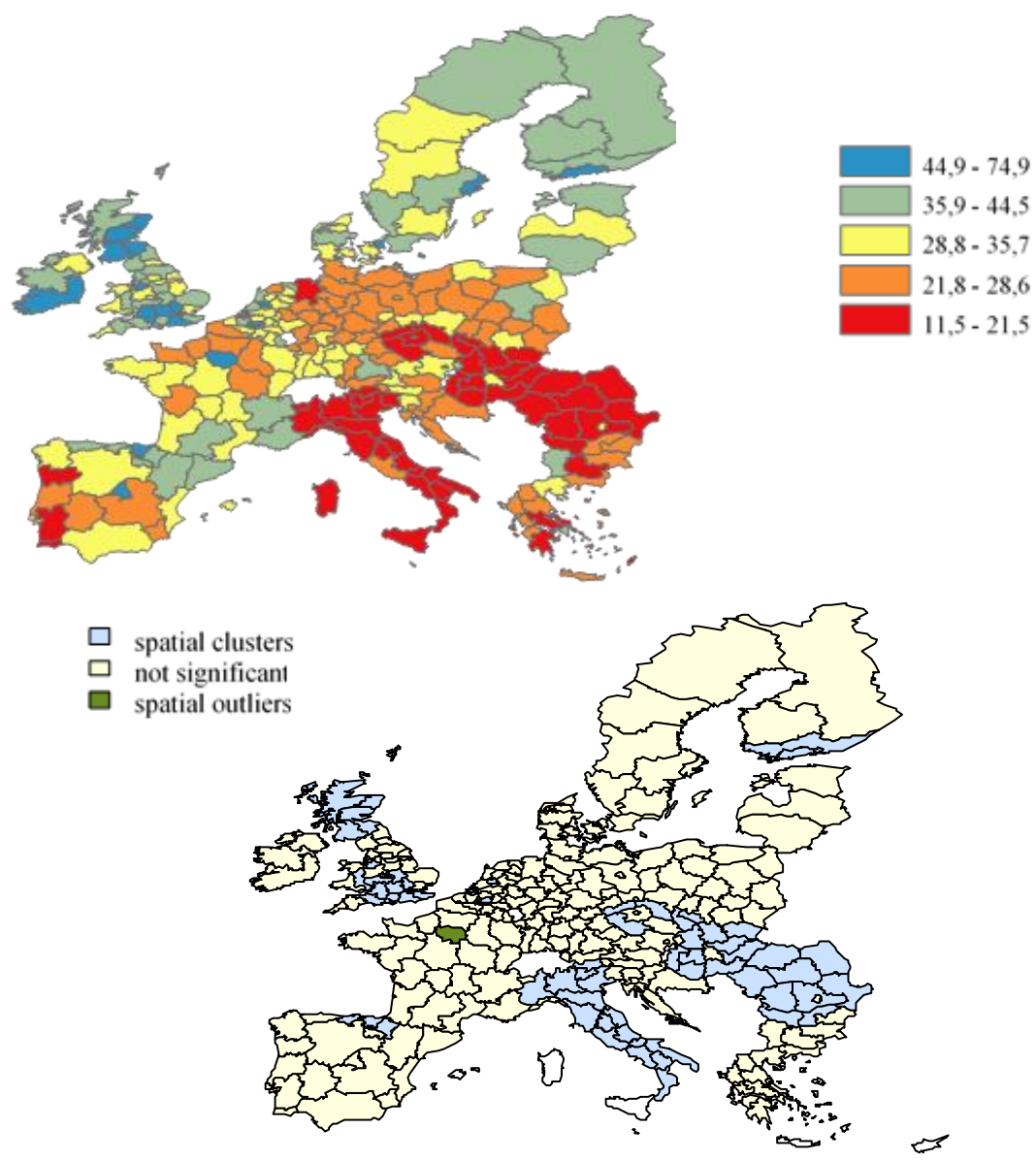

Fig. 2. Spatial distribution of Moran's local statistics (bottom) and clusters (upper) of NUTS-2 EU regions for the ETER in 2016.

The structure of population aged $25-64$ by educational attainment level (tertiary education (levels 5-8)) (ETER): the level of population education is important from the perspective of strengthening regional smart specializations based on innovative solutions, knowledge and modern technology achievements. In case of this phenomenon the strong clustering tendency is presented by the regions characterised 
by a particularly low share of tertiary education graduates. Less than $20 \%$ population presenting tertiary education level lived in the regions creating clusters in the area of Italy, the Czech Republic, Slovakia, Hungary, Bulgaria and Romania. The most favourable situation, from the perspective of tendency towards creating regional clusters and characterised by the high level of population education (tertiary education) was recorded in British regions, in north-eastern Spain and in the south of Finland. In some of these regions the share of tertiary education graduates reached almost $75 \%$.

Participation rate in education and training (LL): the inclination towards upgrading vocational qualifications shows very strong tendency towards creating spatial clusters which overlap the administrative borders of particular countries. The population of France, Denmark, Sweden, Finland, Belgium and the Netherlands are most willing to upgrade their qualifications. In these regions the percentage of population improving qualifications ranged from $17 \%$ to $31 \%$.

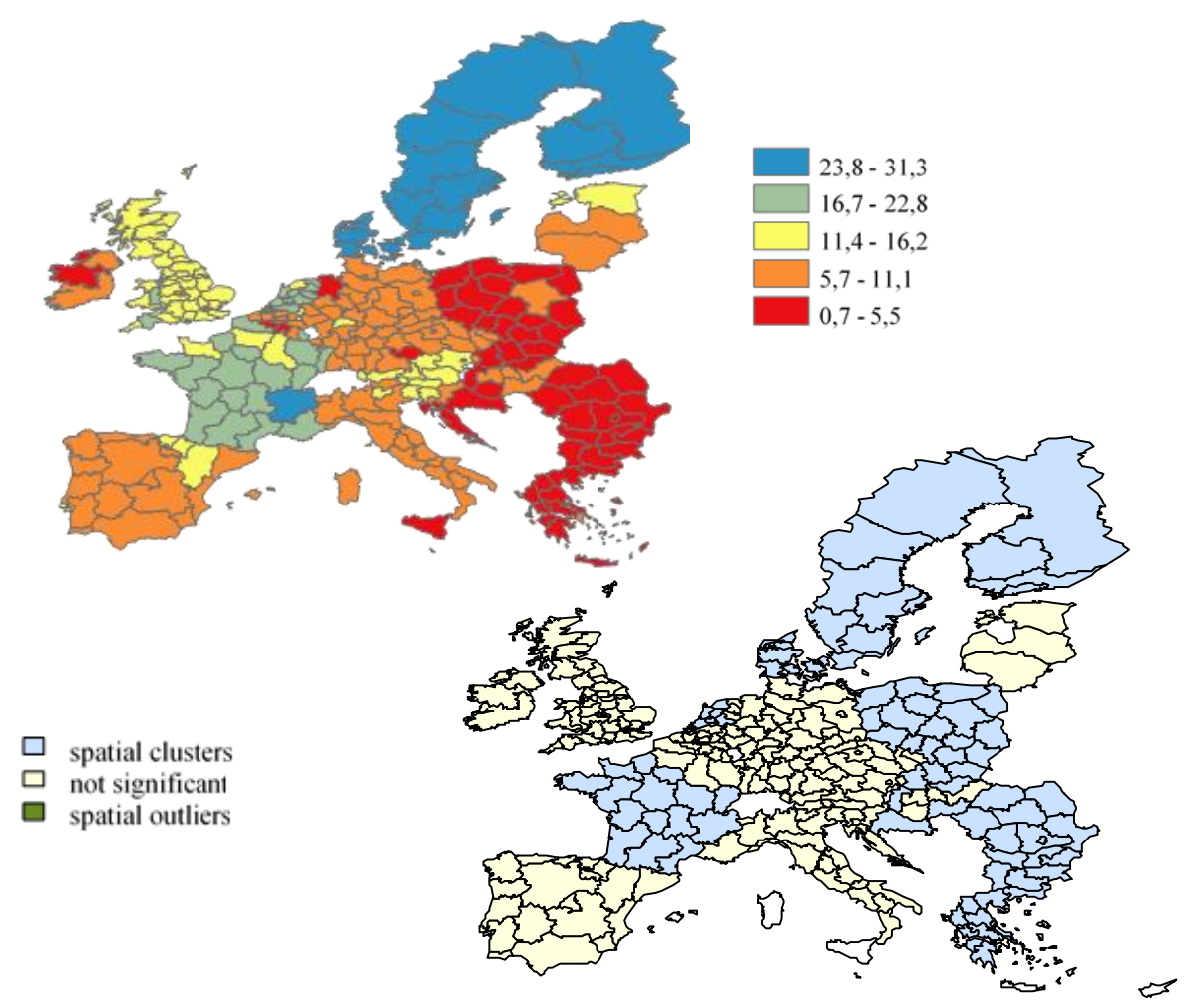

Fig. 3. Spatial distribution of Moran's local statistics (bottom) and clusters (upper) of NUTS-2 EU regions for the LL in 2016. 
The smallest number of population participates in life-long learning in the area of Poland, Slovakia, Hungary, Croatia, Bulgaria, Romania and Greece. In most regions of these countries the respective percentage is less than $5 \%$ of population.

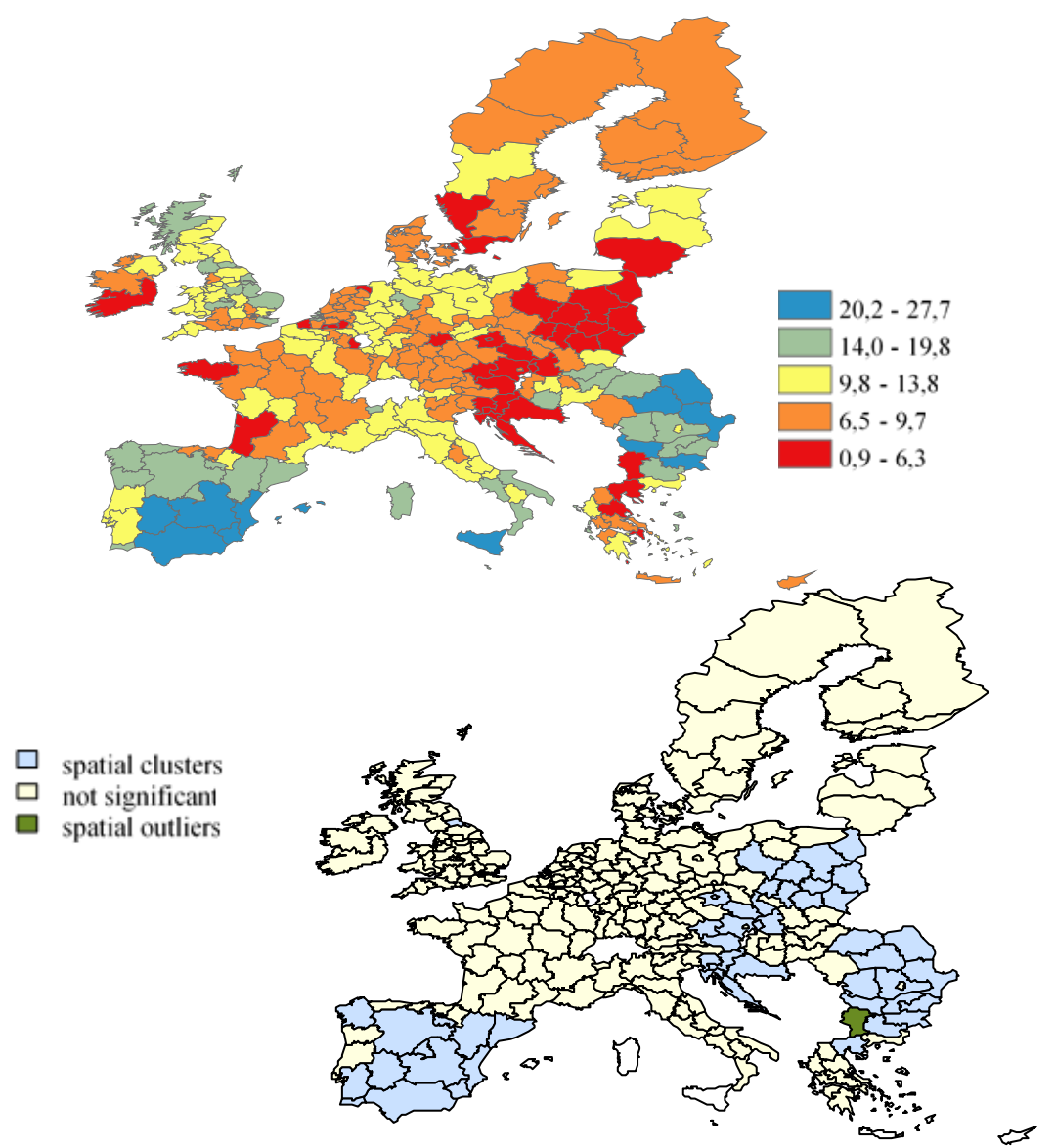

Fig. 4. Spatial distribution of Moran's local statistics (bottom) and clusters (upper) of NUTS-2 EU regions for the EL in 2016.

Early leavers from education and training (EL): in case of people aged 18-24 who leave education early two clusters presenting a very unfavourable situation are visible, where approx. $20 \%-30 \%$ of people represent early leavers. These two spatial clusters cover (1) Romanian and Bulgarian regions and also (2) Spanish and Portuguese regions. A large cluster, characterised by a very favourable situation, is created by the regions located in the belt of Polish, Czech, Austrian, Slovenian and Croatian regions. Moreover, a small cluster in the area of Great Britain can be identified, around the region of Tees Valley and Durham.

Young people neither in employment nor in education and training (aged 18 - 24) (YUEN): The situation of young people aged 15-24 who have left formal education 
with at most lower secondary education and who are not employed nor engaged in any kind of further education or training in the European Union is spatially highly diversified. The most favourable situation is characteristic for middle areas of the Netherlands, Belgium, Germany and the Czech Republic. In turn, in the area of 3 southern European clusters (southern Spain, Italy and in the area of Greece, Romania and Bulgaria) the percentage of young people neither in employment nor in education and training frequently exceeds $20 \%$ reaching even $45 \%$.

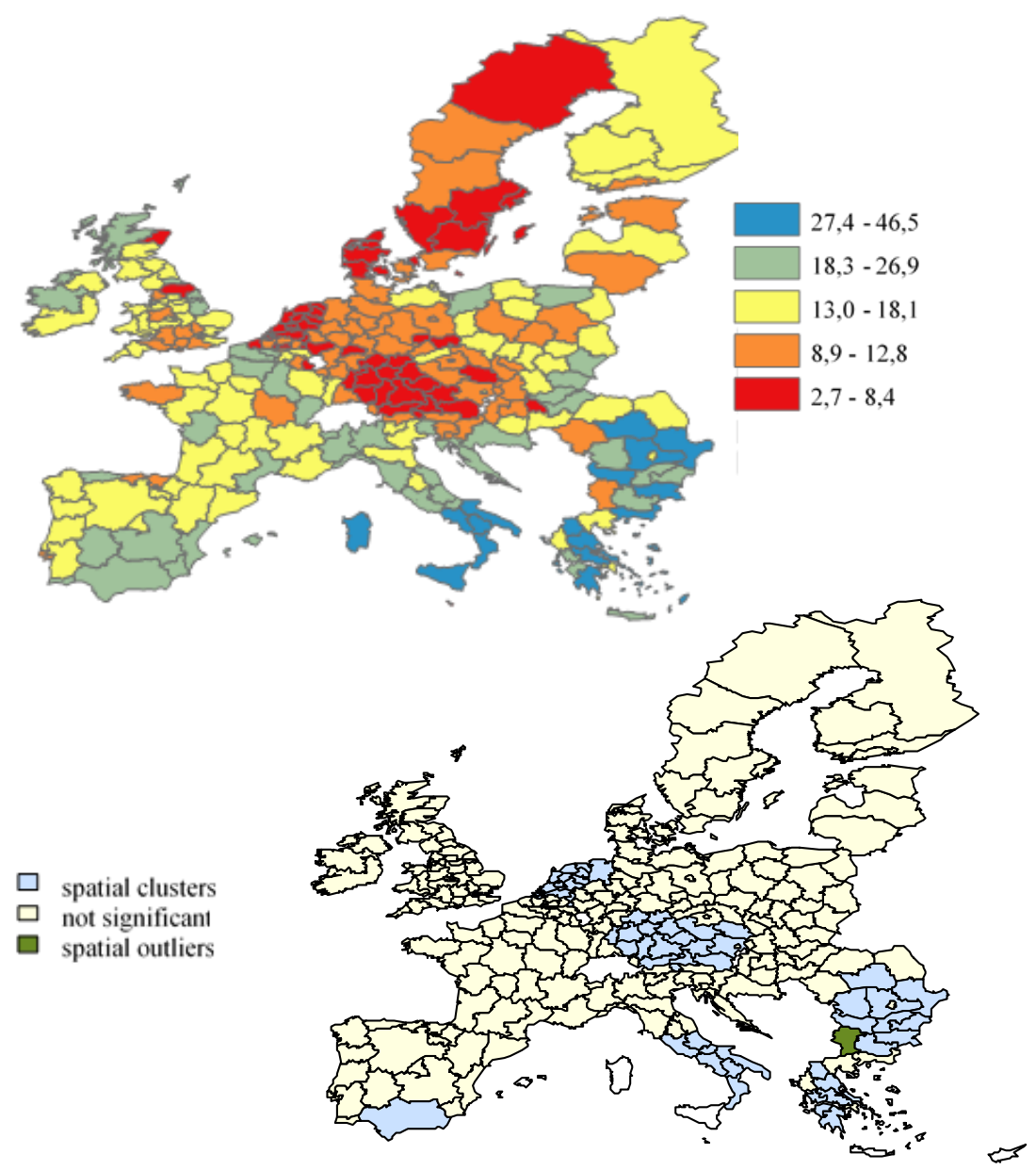

Fig. 5. Spatial distribution of Moran's local statistics (bottom) and clusters (upper) of NUTS-2 EU regions for the YUEN in 2016.

Similar conclusions can be drawn from the distribution of Moran's local statistics for the employment rates of young people neither in education nor training (aged 15-34). The difference is that there is an additional group of regions in southern Sweden characterised by a favourable situation. 

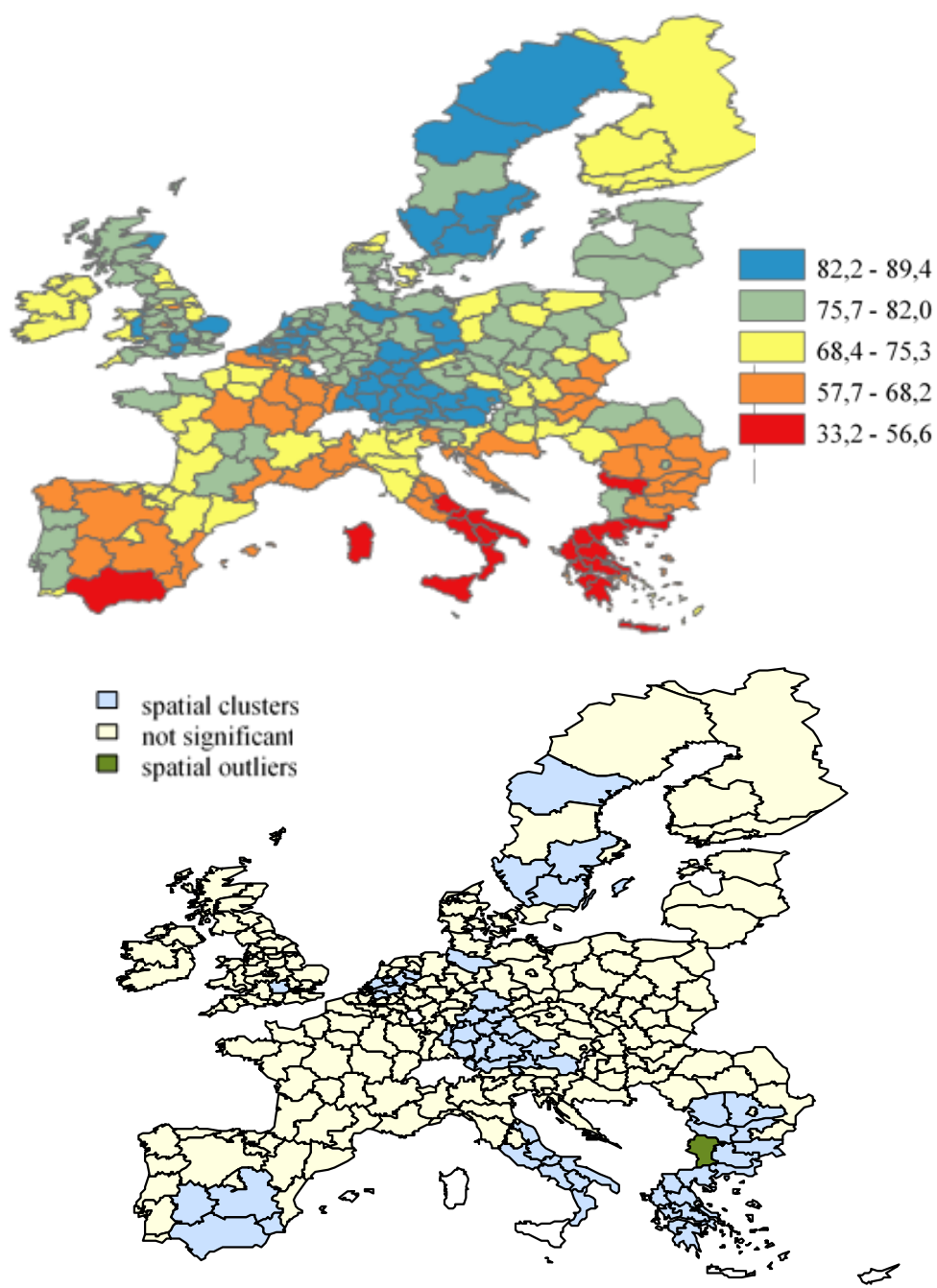

Fig. 6. Spatial distribution of Moran's local statistics (bottom) and clusters (upper) of NUTS-2 EU regions for the YEMPL in 2016.

\section{Summary}

The obtained research results facilitate defining the specific nature of regional groups identified with regard to indicators of educational potential and the situation of youth at the labour market.

Positive values of Moran's I Global indicate strong tendencies for cluster development, primarily in the participation rate in education and training and employment rates of young people neither in education nor training. The lower 
tendency for clustering was observed in case of early leavers form education and training.

The analysis of spatial autocorrelation of educational potential shows the development of clusters characterised by high or low level of its particular components. It seems, however, that the grouping tendency of regions featuring a favourable situation is smaller. More numerous clusters are created by the regions presenting an unfavourable situation.

The analysis shows a well-developed educational potential of the NUTS-2 European regions located in the northern and central part of Europe. The best situation is characteristic for the Scandinavian and British regions, whereas much worse is recorded in the southern ones, primarily Italian (south of the country), Greek, Bulgarian, Romanian and Spanish regions. Low educational potential was accompanied by a relatively weaker position of young people on the labour market, manifested by a higher unemployment rate along with low employment rates for those who did not continue their education.

The obtained results confirm the significance of education for the development of labour market for young people.

Acknowledgements. The study was funded within the framework of the National Science Centre project 2015/17/B/HS4/01021.

\section{References}

1. Becker, G.S.: Human Capital: A Theoretical and Empirical Analysis, with Special Reference to Education. 1st edn. National Bureau of Economic Research, New York (1964).

2. Chevalier, A., Lindley, J.: Over-Education and the Skills of UK Graduates. Statistics in Society 172(2), 307-337 (2009), DOI: 10.1111/j.1467-985X.2008.00578.x.

3. Cliff, A.D., Ord, J. K.: Spatial Processes: Models and Applications. 1st edn. Pion Ltd, London (1981).

4. Kopczewska, K., Kopczewski, T., Wójcik, P.: Metody ilościowe w R. Aplikacje ekonomiczne i finansowe. 2nd edn. CeDeWu, Warsaw (2009).

5. Kopczewska, K.: Ekonometria i statystyka przestrzenna $\mathrm{z}$ wykorzystaniem programu $\mathrm{R}$ CRAN, 2nd edn. CeDeWu, Warsaw (2007).

6. Maršíková, K., Urbánek, V.: A comparison of educational mismatches across Europe. E+M Ekonomie a Management 18(4), 24-38 (2015), DOI: 10.15240/tul/001/2015-4-002.

7. Moran, P.A.P.: The Interpretation of Statistical Maps. Journal of the Royal Statistical Society 10(2), 243-251 (1948).

8. Novák, V., Vokoun, M., Stellner, F., Vochozka, M.: Institutional analysis of the contemporary regional labour market in the Czech Republic. E+M Ekonomie a Management 19(2), 4-19 (2016), DOI: 10.15240/tul/001/2016-3-001.

9. Oancea, B., Pospíšil, R., Drăgoescu, R. M.: Higher Education and Economic Growth. A Comparison between Czech Republic and Romania. Prague Economic Papers 26(4), 467486 (2017), DOI: /10.18267/j.pep.622.

10. Selowski, M.: Educational capital in a model of growth and distribution, Economic Development Report No. 88, Harvard University, Cambridge, Massachusetts (1968). 
11. Suchecka, J.: Statystyka przestrzenna. Metody analizy struktur przestrzennych. 1st edn. Ch. Beck, Warsaw (2014).

12. Suchecki, B.: Ekonometria przestrzenna. Metody i modele analizy danych przestrzennych. 1st edn. Ch. Beck, Warsaw (2010). 